\title{
Aging of Society and New Medical Technology: The Challenge for Health Insurers to Meet the Expectations of Consumers and Governments
}

Peter Zweifel ${ }^{\star}$

Emeritus, Department of Economics, University of Zurich, Switzerland

*Corresponding author: Zweifel P, Department of Economics, University of Zurich, Switzerland, Tel: +43 4244 20319; E-mail: peter.zweifel@uzh.ch

Received date: May 25, 2015; Accepted date: July 28, 2015; Published date: August 03, 2015

Copyright: (c) 2015 Zweifel P, et al. This is an open-access article distributed under the terms of the Creative Commons Attribution License, which permits unrestricted use, distribution, and reproduction in any medium, provided the original author and source are credited.

\begin{abstract}
During the past decades, new medical technology has been cost-increasing rather than cost-reducing, unlike technological innovation in industry. New medical technology thus has importantly contributed to the surge in healthcare expenditure (HCE), which falls also on health insurers both social and private. At the same time, medical advances continue to result in increasing life expectancy and improved quality of life, creating pressure on health insurers to include them in their list of benefits. However, contributions in particular to social health insurance have not kept pace with the promised future benefits, causing a financing gap in most Western countries.
\end{abstract}

In this situation, health insurers are under pressure from two sides. One the one hand, governments expects them to slow the rise in HCE and in contributions. On the other hand, the insured seem to be keen to have access to the latest medical innovations. This conflict of interest is exacerbated by the suspicion occasioned by the finding that HCE increases substantially with closeness to death regardless of age, reflecting the use of medical innovation benefitting people who do not survive for long. HCE reflecting use of the latest medical technology therefore would often constitute an investment in health of very limited return.

This contribution seeks to shed light on these issues. Its point of departure is an ideal of (Western) man, viz. 'to remain perfectly healthy and to drop dead when the time comes'; however, there are cultural differences. This desire induces efforts to bridge the gap between effective and ideal health status, which is most wide just prior to death. Therefore, much medical care is employed precisely then, resulting in a 'cost explosion just before death'.

Now social insurers, being monopolistic schemes, can resort to a variety of measures to reign in the rise of HCE, such as limiting provider choice to cost-conscious physicians and hospitals as in Managed Care, excluding or at least delaying coverage of new medical technology, rationing its use (especially by the aged), and imposing copayments. These measures are also available to private health insurers in principle; however, they must be acceptable to their members, who are accustomed to having expanded rather than restricted choice in health care.

Since preferences with regard to health insurance cannot be measured easily, this paper presents evidence from four experiments of the discrete choice (DCE) type, where respondents are made to repeatedly choose between a status quo and a hypothetical alternative. The first DCE suggests that both managed care-type restrictions an copayments are rejected by members of social insurance both in the Netherlands and Germany, although not always most strongly by the older ones. To overcome this resistance, consumers would have to be compensated substantially by reduced health insurance premiums. The second study shows that at least among Swiss consumers, a delay of a mere two years in access to new medical technology would also have to be compensated by premium reductions of more than 30 percent in the top age group. Turning to specific cases of medical innovation, a DCE involving elderly Swiss citizens finds that their willingness to pay for a hip protector designed to reduce their risk of breaking the femur is negative. Therefore, including hip protectors in the benefit list of health insurance would not have made sense at the time. The fourth study goes all the way to apply the cost-benefit criterion to a medical innovation. It pits estimated willingness to pay by German members of social insurance against the extra cost (and hence insurance contribution) caused by including a new drug for the treatment of diabetes in the benefit list. If this value exceeds the extra cost, a private insurer can safely accept the innovation without running the risk of members cancelling their policies because their willingness to pay for the new medical technology falls short of its cost in terms of premium. Thus, the benefit-cost criterion helps insurers both social and private to meet the expectations of their members (who want access to innovation but dislike paying higher contributions) and governments (who want to see HCE stabilized).

\section{Introduction}

During the past decades, new medical technology has been mainly cost-increasing rather than cost-reducing, unlike technological change in industry. New medical technology has importantly contributed to the surge in healthcare expenditure (HCE), which also falls on health insurers both social and private [6]. At the same time, medical advances continue to result in increasing life expectancy and improved quality of life, creating pressure on health insurers to include them in their list of benefits [1]. However, contributions in particular to social 
health insurance have not kept pace with promised future benefits, causing a long-term financing gap in most Western countries [2].

In this situation, health insurers are under pressure from two sides. On the one hand, governments expect them to slow the rise in HCE and in contributions. On the other hand, the insured seem to be keen to have access to the latest in medical innovation. This conflict of interest is exacerbated by the suspicion that medical innovations benefit people who do not survive for long. The reason for this suspicion stems from the finding that HCE increases with the proximity to death regardless of age [3]. Use of latest medical technology resulting in a 'cost explosion just before death' would appear to be an investment in health of doubtful value.

This contribution seeks to shed light on these issues. Its point of departure is an ideal of (Western) man, viz. 'to remain perfectly healthy and to drop dead when the time comes' [4,5]. This desired age profile of health status has become known as 'rectangularization'. It implies that the gap between effective and ideal health status is most wide just prior to death. Seeking to close this gap, individuals use a great deal of medical care just before death, resulting in the 'cost explosion just before death' cited above. Now social insurers, being monopolistic schemes, can resort to a variety of measures to rein in the rise of HCE. One popular way has been to impose consistent with Managed Care-type restrictions of provider choice, meaning that patients have to see a gatekeeping physician first, or have to choose from a list of preferred providers who are at financial risk and therefore have an incentive to seek out low-cost treatment alternatives. Another alternative is excluding or at least delaying coverage of new medical technology, rationing its use (especially by aged patients), and imposing copayments. These measures are also available to private health insurers in principle. However, they must be acceptable to their members, who are accustomed to having more rather than less choice in health care.

Since preferences with regard to health insurance cannot be measured easily, the evidence presented in this paper is of the discrete choice experiment (DCE) type. Participants in a DCE are made to repeatedly choose between a status quo and a hypothetical alternative. In economics, the golden standard is actual choices, where consumers have to bear their financial consequences of their actions. However, many types of health insurance policy are not available in a given country. Therefore, DCEs may provide some second-best evidence. The author may be forgiven for citing four studies he has been involved in. While there would have certainly been other references, these four studies are especially topical because they seek to measure the preferences of consumers with regard to health insurance and access to medical innovation.

The first study concerns managed care-type restrictions of provider choice such as gatekeeping by physicians and a list of preferred providers imposed by health insurers. In the Netherlands and Germany, these restrictions are opposed also by members of social insurance [7]. The second work revolves around delaying access to new medical technology in an attempt to achieve cost savings. At least in the case of Swiss consumers, a delay of just two years would have to be compensated by a substantial reduction in premiums [8]. In the third study, focus shifts to a particular medical device, namely a hip protector designed to prevent fractures of the femur. Since estimated willingness-to-pay values are found to be negative across all age groups considered, its inclusion in the benefit list of Swiss social health insurance would not have made sense [9]. Finally, the fourth study goes all the way to apply the benefit-cost criterion for deciding whether or not to add a new preparation for the treatment of diabetes to the benefit list of German social health insurance [10]. This criterion is of even higher relevance to private than to social health insurers because their members have a choice. If their willingness to pay for a medical innovation exceeds the extra premium caused by the added cost, they are happy to see the innovation included in the benefit list of the insurer; otherwise, they may cancel their policy. In this particular instance, willingness-to-pay values of the majority were found to match the (expected) extra cost associated with coverage of the treatment. Thus, most members can be expected to accept the increase in contributions necessary to finance the new preparation. More generally, the benefit-cost criterion enables health insurers to serve as the intermediaries between their clients (who want access to medical innovation but dislike paying higher contributions) and governments (who want to see HCE stabilized).

The plan of this paper is as follows. The next Section 2 expounds the ideal health profile ('remain perfectly healthy before dropping dead') of Western man and its consequences in terms of the demand for HCE in general and medical innovation in particular. The so-called Red Herring hypothesis, stating that the proximity of death rather than age is the main driver of this demand, is also outlined. If true, the Red Herring hypothesis has important implications for health insurers. Since age continues to be the best indicator of proximity to death at any given point in time, it is the aged consumers who need to be won over for any new policies in health insurance designed to mitigate the 'cost explosion just before death'. Therefore, a Section 3 presents experimental (DCE) evidence suggesting that restrictions of the MC type would have to be compensated by substantial premium reductions to be acceptable to German and Dutch consumers. In a subsequent Section, the focus shifts to medical innovation. A general delay of access to new therapies of no more than two years would have to be highly compensated, according to another DCE. However, this does not imply that all new therapies are welcome; in the case of the hip protector, another DCE reveals negative willingness-to-pay values throughout. By way of contrast, a new diabetes preparation is shown to trigger willingness to pay coming close to its extra cost among the non-diabetic majority of the insured, justifying its inclusion in the benefit list if subject to some copayment. Concluding remarks and some suggestions for health policy are offered in the conclusion section.

\section{The Ideal Health Profile and the Demand for Health Care and Medical Innovation}

Individuals at least in Western culture seem to share a common goal, viz. to remain in perfect health as long as possible and to drop dead when the time has come [4,5] for the importance of cultural differences]. In medical jargon, they seek to attain perfect 'rectangularization' of their age-related health profile (see panel A of Figure 1). The (stylized) profile No. 1 depicts the current situation in developed countries. It comes close to the ideal in that the health of newborns is sufficiently under control to avoid infant mortality, while deaths before the age of 70 have become the exception. Indeed, judging from the rectangularization of survival curves, [11] conclude that since 1960 citizens of OECD countries have generally been increasingly able to avoid extreme losses of health resulting in death. In a similar vein, [12] estimate that two-thirds of the longevity gained since the early 1960 's in major industrial countries are disability-free. If these trends are to continue, rectangularization of the health profile 
will become ever more perfect, combined with a higher age at death (see profile No. 2 of panel A).

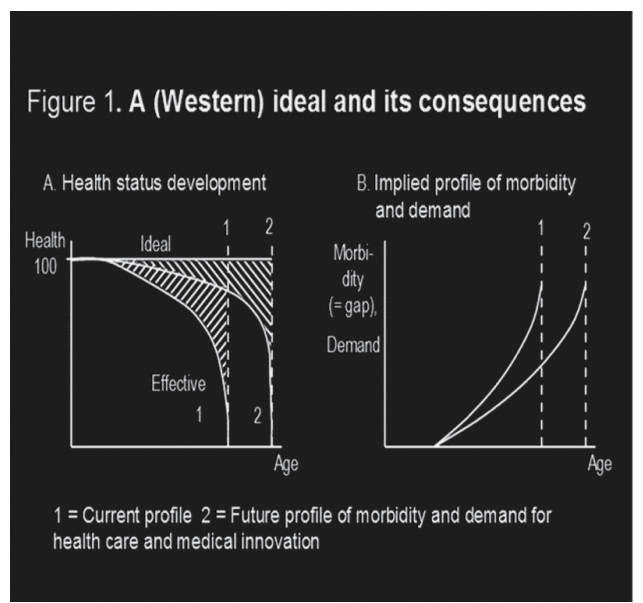

Figure 1: A (Western) ideal and its consequences.

Note that the shaded areas in panel A of Figure 1 symbolize healthy life years lost, caused by the gap between effective and ideal health status. This gap thus reflects morbidity; its implied age profile is shown in panel B of Figure 1. Regardless of whether profile No. 1 or 2 applies, the gap increases by definition when the individual approaches death. Individuals by assumption seek to close this gap using their own resources and medical care. Yet with increasing age, their own efforts (mainly time spent on prevention) become less effective, causing an increased reliance on medical care, in particular of its most innovative variety. For it is medical innovation that allows to close the gap (i.e. overcome morbidity) especially when it is large, i.e. in life-threatening situations. This (Western) view of human behavior thus leads to the Red Herring hypothesis, stating that medical care and especially medical innovation is in highest demand just before death, regardless of age [13].

Contrary to received epidemiological wisdom, the Red Herring hypothesis claims that it is not age that drives the demand for medical care but closeness to death. In addition, a comparison of the current profile No. 1 and the future profile No. 2 of panel B of Figure 1 suggests that this demand (and hence HCE) will become even more concentrated towards the end of life, given unchanged incentives. However, if the insured were made to bear a higher share of their HCE shortly before death (or were to benefit from any cost savings achieved through lowered premiums), this trend could be broken. At the same time it should be noted that the expensive final years of life will be distributed over a longer life span, thus rendering future cohorts less costly. Unfortunately, this is of little consolation to governments and health insurers. On the one hand, governments are not willing to adopt a planning horizon of 70 years and more; on the other hand, health insurers know too well that medical innovation will almost certainly continue to inflate HCE in the meantime.

\section{Conclusion 1}

In view of the Red Herring hypothesis, demand for medical care in general and medical innovation in particular will not only continue to grow but will increasingly be concentrated during the last years of human life.
If true, Conclusion 1 implies quite a challenge for governments that will spill over to health insurers both social and private. Until rather recently, politicians have been able to win elections by promising 'Health for All', the popular slogan of the World Health Organization (WHO). Accordingly, public HCE claimed an increasing share of government expenditure. In France for instance, this share stood at about 13.3 percent in 1970 , rose to 15.1 percent in 1980 , and attained 19.6 percent by 2000 (Fraser Institute, 2009; Kaiser Family Foundation, 2011). Similarly in the United States, it increased from 6.8 percent in 1970 to 19.6 percent in 2000 (usgovernmentspending.com). Over the same time span, government expenditure accounted for an increasing share of GDP. In France, this share rose from an estimated 40.5 percent in 1970 (extrapolated from the change between 1975 and 1980 ) to 51.6 percent in 2000; in the United States, it rose from 31.0 to 32.6 percent of GDP. The result of these two trends has been a rapid expansion of the public health share in the GDP in both countries (from 5.4 to 10.1 percent in France and from 2.1 to 7.3 in the United States). An expansion of this type has been characteristic of most OECD countries. Small wonder governments have come to realize that the WHO promise 'Health for All' is very costly to keep. They are trying to relieve their budgets from HCE by imposing increased copayments on consumers, making them sign up for Managed Care, and having them purchase supplementary coverage from private health insurers. Examples are the introduction of reference prices for pharmaceuticals (beyond which patients have to pay the extra cost out of pocket) and cutbacks on dental coverage in Germany, the outsourcing of Medicaid populations to private contractors by U.S. states, the imposition of gatekeeping physicians in the Netherlands, and most recently, having private U.S. insurers compete for Medicare Advantage business. However, these measures all fail to address the basic challenge which seems likely to become even more acute in the future, viz. the 'cost explosion just before death'.

When becoming aware of this challenge, governments will become increasingly loath to permit the use of medical care, let alone of latest medical technology, by citizens who will not be alive a few months later. The payoff to such 'investments in health' just appears to be too limited to justify the expense. Yet, the analysis of the preceding section suggests that citizens will want to undertake these investments - at least as long as they are exposed to unchanged incentives. This conflict of interest between governments and citizens is likely to spill over into demands for health insurers both public and private to come up with solutions for reining in the 'cost explosion just before death'. However, private insurers cannot simply impose new types of policy. Indeed, they have to overcome two difficulties.

(1) Their clients can choose their insurer. If they dislike a new type of policy, they may cancel it and go elsewhere;

(2) Their clients are also used to having an enlarged choice of healthcare providers and often therapies. They will resist restrictions of choice even more strongly than the socially insured.

\section{Can the Resistance against Managed Care-Type Restrictions be Overcome?}

The evidence to be presented below concerns restrictions of the managed care-type such as gatekeeping by physicians and lists of preferred providers. It is experimental, coming from hypothetical rather than actual choices. Admittedly, experimental evidence is second best for economists, their gold standard being effective choices. However, health insurers have been hesitant to introduce product 
Page 4 of 8

innovations of the MC type, likely because of the two difficulties cited above. The experiments to be reported are of the discrete choice type (DCE); they make respondents repeatedly choose between a status quo and an alternative with changing attributes.

One DCE involved about 600 respondents from the Netherlands in 2006, after a major pro-choice reform. It is of particular interest for three reasons. First, the 'firewalls' between social and private health insurance had been torn down as part of the reform, creating a level playing field for the two types of competitors. Second, Dutch citizens had been subject to gatekeeping by physicians, a MC feature, for several years. Therefore, offering them a (hypothetical) return to free physician choice might not trigger too much willingness to pay (WTP). Third, a similar DCE had been performed in Germany, where the status quo continues to be free physician choice, while policymakers are considering introducing gatekeeping as a $\mathrm{MC}$ feature.

Table 1 contains a few surprises. First, the choices made by the Dutch respondents reveal that after years of gatekeeping, they would still display positive WTP for a return to free physician choice. Interestingly, the WTP value is maximum in the middle age group (Euro 106/year) rather than the oldest (Euro 67/year). Conversely, although enrolled in social insurance, the oldest German age group in the sample would have to be compensated even at the tune of Euro 158/year for accepting a transition from free physician choice to gatekeeping. Likely due to its lock-in effect, a physician network is resisted by the Dutch across the three age groups in spite of their experience with gatekeeping. Not surprisingly, this is even truer for the Germans, who have free physician choice as their status quo. Compensation values jump up in case the health insurer was to compose a physician list also including specialists. Here, the lock-in effect is apparently most feared by respondents in the highest age group, resulting in a required compensation of Euro 174/year among the Dutch and even Euro 375/year among the Germans. To put these WTP values in perspective, they amount to some 4.7 percent of average annual contribution in the Netherlands (Euro 3,700 in the sample, not counting public subsidies) and 12.5 percent of the employee share of the contribution in Germany (Euro 3,000, topped up by employers).

\section{Conclusion 2}

In the Netherlands and Germany, MC type restrictions such as gatekeeping by physicians, a physician network, and a physician list including specialists would have to be compensated by a reduction of the contribution to health insurance. While the highest age group does not necessarily resist these features more strongly than the others, it does so in both countries with respect to the physician list.

However, health insurers could also reign in moral hazard towards the end of human life by offering policies with changed financial incentives. The classic tool of course is the deductible, to be set at Euro 500 annually in both DCEs. This would have to be compensated very highly across all age groups in the Netherlands, reaching a maximum of Euro 448/year in the middle age group. Among the German respondents, resistance is less marked, with required compensation reaching Euro 311/year, again in the middle age group. One explanation for this striking difference is the fact that as a consequence of changes in short-term disability insurance, Dutch workers have been exposed to substantial financial risk whereas their German counterparts continue to enjoy ample protection during a full year.

\begin{tabular}{|l|l|l|l|l|l|l|}
\hline & \multicolumn{3}{|c|}{ Netherlands (NL) } & \multicolumn{3}{c|}{ Germany (D) } \\
\hline & Age & Age & Age & Age & Age & Age \\
\cline { 2 - 7 } & $<41$ & $\mathbf{4 1 - 5 5}$ & $\mathbf{7 5 5}$ & $\mathbf{7 4 3}$ & $\mathbf{4 3 - 5 9}$ & $>\mathbf{5 9}$ \\
\hline $\begin{array}{l}\text { Free physician } \\
\text { choice (NL) }\end{array}$ & 67 & 106 & 67 & n.a. & n.a. & n.a. \\
\hline $\begin{array}{l}\text { Gatekeeping by } \\
\text { physician (D) }\end{array}$ & n.a. & n.a. & n.a. & -115 & -100 & -158 \\
\hline $\begin{array}{l}\text { Physician } \\
\text { network }\end{array}$ & -92 & -71 & -61 & -212 & -208 & -219 \\
\hline $\begin{array}{l}\text { Physician list, } \\
\text { including } \\
\text { specialists }\end{array}$ & -125 & -139 & -174 & -346 & -361 & $-\mathbf{3 7 5}$ \\
\hline $\begin{array}{l}\text { Annual } \\
\text { deductible } \\
\text { 500 }\end{array}$ & -359 & -448 & -440 & -243 & -311 & -180 \\
\hline $\begin{array}{l}\text { Rebate for no } \\
\text { claims } € 500 \\
\text { (bonus) }\end{array}$ & 77 & -59 & -44 & 326 & 328 & 436 \\
\hline $\begin{array}{l}\text { Preference for } \\
\text { status quo } \\
\text { (WTP<0) }\end{array}$ & -162 & -234 & -479 & -329 & -407 & -940 \\
\hline
\end{tabular}

Table 1: Mean WTP values, Netherlands (2006) and Germany (2005, socially insured only), by age group, in Euro/year.

aAll values are statistically distinguishable from zero at a confidence level of 99 percent or better (except three values in italics); values in bold indicate values that are more strongly negative among the highest age group than for the others [14].

Therefore, the Dutch are subject to a higher 'pain of risk-bearing' [15] than the Germans since their Euro 500 deductible may accumulate with the income loss due to short-term disability. Likely for the same reason, the Dutch are ambivalent with regard to an annual premium rebate for no claims amounting to Euro 500, although they had a bonus of this type reaching a maximum of Euro 255 in the status quo (it has been abandoned since). The Dutch WTP values in Table 1, while negative, are not distinguishable from zero in any age group. By way of contrast, the Germans seem to like the bonus proposal, their positive WTP attaining its maximum in the top age group (although the difference from the other two groups is statistically insignificant). Being highly protected from the income risk associated with short-term disability, they seem to be prepared to pay the first Euro 500 of HCE themselves in order to save their bonus. Yet the Dutch and Germans agree that a bonus is far more acceptable than a deductible of the same amount. At first blush, this is puzzling: After all, for preserving the bonus, they would have to come up with the first Euro 500 themselves; therefore, bonus and deductible of the same amount appear to be equivalent. However, patients in fact are exposed to two losses. First, they have to bear the loss of health, and second, a financial loss of up to Euro 500. In the case of a deductible, Euro 500 must be paid under all circumstances, whereas in the case of a bonus, payment can be deferred to the following years in the guise of higher premiums. In this way, patients can shift the second loss to a future period, which is of value to risk-averse individuals. 


\section{Conclusion 3}

Limiting moral hazard towards the end of human life by a deductible meets with marked resistance both in the Netherlands and Germany. Required compensation in term of a premium reduction required would be especially high among the Dutch, likely because they already are exposed to an income risk in the event of short-term disability. By way of contrast, offering a rebate for no claims in the same amount would be welcomed by the Germans, including their highest age group.

Resistance against a higher deductible was also found in a DCE involving Swiss citizens in 2005 [16]. One of the changes considered was an increase from the legal minimum of CHF 230 annually to $\mathrm{CHF}$ 1,500 ( 1 Swiss franc $\mathrm{CHF}=0.8$ US $\$$ at 2005 exchange rates). The top age group (63 and higher this time) would have to be compensated by CHF 720 or some 22 percent of average premium to voluntarily accept this increase, compared to CHF 456 in the 25-39 age group.

It is tempting to conclude that limited reductions in premium are sufficient to win the aged over for new types of policies designed to limit moral hazard in the proximity of death. However, one needs to consider the bottom line of Table 1. The values exhibited there indicate that a substantial additional compensation would have to be offered to make consumers break away from the status quo. Among Dutch respondents, this amount reaches Euro 479/year in the highest age group, among their German counterparts, even Euro 940/year. Evidently, aged citizens of both countries display extremely strong status quo bias. Two details are noteworthy. First, status quo bias is much stronger in Germany than in the Netherlands. One likely reason is that Germans had been exposed for about a decade to ever-changing reform proposals that never succeeded. By way of contrast, the Dutch reform of 2006 had mandated every citizen to actually choose a health insurance policy; just keeping a policy by default was not permitted. Therefore, the Dutch respondents had been made to bear the cost of decision-making at the time the DCE was fielded in 2006. Second, status quo bias increases strongly with age in both countries. This commonly found phenomenon has sometimes been interpreted as a sign of irrationality. However, both its existence and its increase with age reflect sound economic behavior. After all, studying and getting to understand a new health insurance policy constitutes a substantial investment of time which needs to be compensated; hence the negative WTP values. The payoff to this investment could be a reduction in future premiums. Yet for older consumers the present value of this potential stream of benefits is less than for younger ones precisely because they are closer to death.

\section{Conclusion 4}

The decisive challenge facing a health insurer seeking to introduce policies designed to mitigate the 'cost explosion just before death' may well be to overcome consumers' status quo bias, which may depend on the recent history of (attempted) healthcare reforms but is generally most marked among the older age groups.

\section{Access to Medical Innovation in Particular}

Ever since [6], there has been growing recognition that new medical technology may be the main driving force behind the rise of HCE. Using time-series analysis for filtering out common trends in GDP and HCE, [17] came to a similar conclusion. More recently, the U.S. [18] has attributed about 50 percent of the growth of HCE in the United States to technological innovation in medicine. It should be noted, however, that the pace of change in medical technology is in turn influenced by health insurance. Healthcare providers are encouraged to use the newest therapies even if they are more costly since their patients, being covered by health insurance, are little affected financially [19]. In the case of statins, [20] indeed find that both the probability and the extent of their use depends on the insurance status of the patient. In a final sample consisting of more than 210,000 U.S. individuals covering the years 1995 to 2005, they estimate effects on probability of use ranging from 1.9 percentage points (private insurance only) to 3.7 points (public insurance only), compared to the 'no insurance' benchmark. And given any use of statins, the number of defined daily doses increases by up to 13.2 percent beyond the value associated with 'no insurance'.

Apparently, there is a spiraling interdependence between technological change in medicine and health insurance. On the one hand, new medical technology drives up HCE and hence insurance premiums; on the other hand, ample health insurance coverage facilitates technological change in medicine. To slow this spiral, it is therefore important to know the types of new medical technology that are sufficiently valued by consumers to be financed by health insurance. Since most policies cover the same set of therapies in a given country, it may again be worthwhile to consider experimental evidence as a second-best source.

A DCE involving Swiss citizens is reported in panel A of Table 3. WTP values are shown for accepting that social insurers generally delay the inclusion of new therapies in their benefit list by two years. The status quo is characterized by almost no delay after the Federal Medication Committee has recommended adoption of a new product or therapy. The compensation required for accepting this delay amounts to CHF 45/month in the lowest age group and rises to the significantly higher value of CHF 101/month among respondents aged 40 to 64 . Interestingly, there is an indication that it might fall to $\mathrm{CHF}$ 83 for the highest age group, although the difference from CHF 101 lacks statistical significance. To put the CHF 83 into perspective, it equals 31 percent of the nationwide average premium at the time (2005); health insurers would therefore have to offer a reduction in premiums of at least 31 percent to make their aged members voluntarily wait for just two years before gaining access to the newest medical technology. This means that the cost savings achievable thanks to such a delay must attain 31 percent to be financially viable -a rather stringent requirement. An encouraging finding is that [16], based on another DCE, also report that the top age group resists a delay of this type less strongly than the middle-aged one; therefore, depending on the speed with which the cost of new medical technology comes down after its introduction, consumers with rather short remaining life expectancy might be won over for policies designed to avoid the 'cost explosion just before death'.

A second study, performed in 1996, revolves around a specific medical innovation, albeit of a rather mundane type. A DCE had 522 elderly (non-institutionalized) people choose between the status quo (no hip protector) and a hip protector designed to lower the risk of breaking their femur. The attributes were the amount of risk reduction, ease of handling, wearing comfort, and out-of-pocket price (to which respondents are used because Swiss social health insurance imposes a 10 percent copayment on ambulatory care). While the amount of risk reduction afforded was clearly valued, ease of handling and wearing comfort turned out to be important attributes as well. Since the available brands (among them, HIPS) failed to provide sufficient ease of handling and wearing comfort, they all called forth 
negative total WTP values. Therefore, at the time it made little sense for Swiss health insurers to include any one of the existing brands of hip protector in their list of benefits; being negatively valued, they would not be worn (although product design may have improved since then). The WTP values entered in panel B of Table 2 relate to HIPS ${ }^{\circ}$. Resistance against HIPS seems to increase with age, although the increase fails to reach statistical significance due to small sample size in the two highest age groups. Possibly, respondents considered getting used to wearing a hip protector as an investment which has a shortened payoff time with increasing age and hence proximity to death.

Rather than hip protectors, much medical innovation revolves around pharmaceuticals. Panel $\mathrm{C}$ of Table 2 reports WTP values for a new diabetes treatment derived from a DCE performed in 2007. While lowering the risk of hypoglycemia to a comparable degree as existing alternatives, the new preparation avoids the usual weight gain, does not need to be swung, and offers more flexibility in the timing of injection. There are two modes of financing: Out-of-pocket copayment and a slight increase in the rate of contribution to German social health insurance, to be paid by employees. Four subgroups are distinguished ranging from non-diabetics to type 2 diabetics who need insulin; in return, resulting sample sizes do not permit a classification by age group. Presumably, type 2 diabetics who have to rely on insulin have the shortest remaining life expectancy (or are closest to death, respectively). If they should view getting used to the new treatment as an investment (in a similar way as the potential users of a hip protector), their WTP values are predicted to be comparatively low.

\begin{tabular}{|c|c|c|c|c|}
\hline \multirow[t]{3}{*}{ Panel $\mathbf{A}^{1}$} & \multicolumn{4}{|c|}{$\begin{array}{l}\text { WTP for accepting a delay of two years in access to medical } \\
\text { innovation, Switzerland } 2005, \mathrm{CHF} / \text { month }\end{array}$} \\
\hline & Age 25-39 & Age 40-64 & Age 65+ & \\
\hline & 45 & 101 & 83 & \\
\hline \multirow[t]{3}{*}{ Panel B ${ }^{2}$} & \multicolumn{4}{|c|}{$\begin{array}{c}\text { WTP for HIPS }{ }^{\circledR} \text {, a hip protector for preventing fracture of the } \\
\text { femur }\end{array}$} \\
\hline & Age $70-75$ & Age $76-80$ & Age 81-85 & Age $86+$ \\
\hline & -285 & -389 & -388 & -517 \\
\hline \multirow[t]{2}{*}{ Panel C ${ }^{3}$} & \multicolumn{4}{|c|}{$\begin{array}{l}\text { WTP for new drug for the treatment of diabetes, Germany } \\
\text { 2007, Euro/year }\end{array}$} \\
\hline & $\begin{array}{c}\text { Non- } \\
\text { Diabetics } \\
(\mathrm{n}=602)\end{array}$ & $\begin{array}{c}\text { Diabetics } \\
\text { Type } 1 \\
(\mathrm{n}=202)\end{array}$ & $\begin{array}{l}\text { Type 2, Insulin- } \\
\text { treated }(n=154)\end{array}$ & $\begin{array}{c}\text { Type 2, } \\
\text { Insulin - } \\
\text { naïve } \\
(n=152)\end{array}$ \\
\hline Copayment & $790^{\mathrm{a}}$ & 245 & 318 & 427 \\
\hline Contribution & 232 & 269 & 0 & 171 \\
\hline
\end{tabular}

Table 2: WTP values for access to medical innovation [8-10].

${ }^{1}$ Other attributes: Physician list of three different types, Reimbursement of generics only, No reimbursement of drugs for minor complaints, and No small local hospitals.

${ }^{2}$ Attributes: Reduction in the risk of breaking the femur, Ease of handling, Wearing comfort, Out-of-pocket price.

${ }^{3}$ Sum of attributes with significantly positive WTP values only. Attributes: Change in risk of hypoglycemia, Change in weight, Have to swing (yes/no), Increased flexibility in timing of injection (yes/no),
Amount of copayment, Increase in annual contribution to health insurance.

aWTP values for non-diabetics are weighted by their average estimated probability of acquiring diabetes in the future (equal to 53 percent).

In the case of financing through copayment, WTP values are highest among the non-diabetics (Euro 790/year, after weighting them with their subjectively estimated 53 percent probability of acquiring diabetes in the future). Almost two-third of this value comes from a preference for the alternative, the opposite of status quo bias. One might infer a degree of altruism causing the non-affected to be willing to support those affected by the condition. However, the WTP values of non-diabetics drop considerably (to Euro 232/year) if the innovation is to be financed by an increase in contributions, which would burden them as well. By way of contrast, type 1 diabetics know that they might need treatment before long. As expected, the difference between the two modes of financing vanishes for them (the WTP value of Euro 245/year in the case of copayment is not significantly different from the Euro 269/year in the case of an increase in contributions).

The WTP values among the type 2 diabetics already undergoing insulin treatment are of particular interest because these patients have the shortest remaining life expectancy of the four subgroups distinguished. The closest comparison group probably are type 2 diabetics who are 'insulin-naïve', i.e. who can still do without insulin treatment and therefore have a higher life expectancy. In the case of copayment, patients subject to insulin treatment indeed display a lower WTP value (Euro 318/year) than the insulin-naive ones (Euro $427 /$ year). This is compatible with the view that just learning a new way of insulin treatment constitutes an investment whose payoff needs to be sufficiently high (a condition apparently better satisfied among insulin-naïve than among insulin-treated patients). When turning to the alternative of financing through increased contributions, the results are puzzling. While the insulin-naïve subgroup exhibits a statistically significant WTP value amounting to Euro 171/year, the WTP values pertaining to the insulin-treated subgroup add up Euro $1,000 /$ year, but none of them can be distinguished from zero. For this reason, a zero value is entered for this subgroup in Panel C of Table 3. There seems to be hidden heterogeneity of preferences causing an unexpectedly large degree of dispersion in WTP values and hence overlap with the zero benchmark. This heterogeneity might be due to some patients being aware of the possibility that the attributes distinguished could cause harm with a certain probability, leading them to place little value on them.

On the whole, it is not clear whether WTP for this particular medical innovation increases or decreases with closeness to death. However, two findings stand out. First, seemingly minor innovations may be associated with substantial WTP. For instance, the fact that the new preparation does not need to be swung contributes 22 percent $(72$ out of the Euro 318/year found among the insulin-treated type 2 patients in the case of copayment) to total measured WTP, comparable to the absence of weight gain (Euro 72/year) and clearly more than the reduction in the risk of hypoglycemia afforded by the preparation (Euro 29/year; figures not shown in Table 2). In hindsight, this finding becomes intuitive. A preparation that needs to be swung may fail to deploy is full effectiveness; being relieved of this risk may well be of considerable importance to patients. Second, the data permit to perform a full-blown cost-benefit analysis. While the extra cost of the new preparation is Euro 272/year and patient, WTP values exceed this 
benchmark among three of the four subgroups distinguished when financing is through copayment, the exception being diabetes type 1 patients (Euro 245/year). However, the same subgroup exhibits a WTP value of Euro 269/year if the burden of financing is shared by everyone through a slight increase in contributions. In addition, non-diabetics, the majority of the insured population, exhibit a WTP value of Euro $232 /$ year, which comes close to the extra cost of Euro 272/year. Therefore, applying the cost-benefit standard one is led to conclude that willingness to pay of the socially insured in Germany is sufficiently strong to justify inclusion of this particular medical innovation in the list of benefits of (social) health insurance. In view of the fact that the non-diabetics display a WTP value that is almost 3.5 times greater (Euro 790 rather than 232) if financing is through copayment, it might be appropriate to subject this particular innovation to a modest degree of copayment in order to heed the preferences of those who constitute the majority of the insured.

\section{Conclusion 5}

To mitigate the 'cost explosion right before death', health insurance policies might exclude or at least delay access to new medical technology beyond a certain age. Experimental evidence suggests that the challenge may again be overcoming a marked status quo bias on the part of the aged. In the case of an innovation requiring substantial adjustment (wearing a hip protector), willingness to pay can be negative. In the case of a particular pharmaceutical innovation (new diabetes treatment), it is found positive and high enough to cover the extra cost thorough a slight increase in contributions potentially combined with a modest copayment.

\section{Conclusion}

The point of departure of this contribution is the observation that (Western) man's mirage is to stay perfectly healthy but drop dead when the time has come, resulting in a desire to attain so-called rectangularization of health status. This desire implies that the gap between effective and ideal health status is maximum just prior to death, triggering maximum use of healthcare services and latest medical technology, hence a 'cost explosion just before death'. Taking an ex post stance, many a policy maker will argue that investments in health shortly before death have little return, yet they are undertaken nevertheless because the insured not have to bear the financial consequences of their decisions. This neglects not only the fear of death but also the fact that ex ante, even aged patients may see a substantial probability of returning to a satisfactory health status. Moreover, the 'cost explosion just before death' may reflect provider incentives (who know they have carte blanche since family members of possibly deathbound patients are unlikely to intervene) to an even greater extent than those of the insured. In all, this conundrum constitutes a major challenge to governments who look for ways to relieve their budgets from the cost of public health care, a challenge that is likely to spill over to health insurers both social and private. However, private insurers, being subject to the pressure of competition, must act in accordance with the preferences of their members who are accustomed to having full access to existing and new therapies.

Especially private health insurers thus need to develop new policies that contain incentives for avoiding the 'cost explosion just before death'. These policies stipulate MC type restrictions of provider choice, a delay in access to newest medical technology, or an increase of copayment. Because insurers cannot know proximity to death, they have to win over the aged with their marked status quo bias. Indeed, experimental evidence from the Netherlands and Germany suggests that while all age groups require compensation in terms of a reduced contribution to health insurance to accept restrictions in provider choice, this compensation increases with age. Still, status quo bias is much weaker in the Netherlands (where a pro-competitive reform had been enacted) than in Germany, pointing to the importance of the policy environment. On the whole, MC type policies must achieve substantial cost savings, to be passed on in the guise of premium reductions to consumers, to be accepted by members of (private) health insurance.

With regard to access to medical innovation, evidence from Switzerland suggests first that introducing a general delay of two years before new therapies are covered by Swiss social insurance would require compensation amounting to some 31 percent of average premium to be acceptable to those of age 65 and older. Interestingly however, it is the middle age group that would have to be compensated most for such a delay. Second, the mundane device of a hip protector designed to avoid fractures of the femur was found to meet resistance by the elderly. While they put positive value on the decrease in the risk of fracture, available brands afforded too little ease of handling and wearing comfort, resulting in a negative overall willingness to pay. Finally, measurement of willingness to pay for a new diabetes preparation in Germany can be used to perform a cost-benefit analysis. Since the majority of non-diabetics would be prepared to pay as much as the extra cost of the preparation even if contributions would go up accordingly (provided diabetics contribute with some limited copayment), the cost-benefit criterion is satisfied, justifying inclusion of this particular preparation in the benefit list of German health insurance. In sum, there are medical innovations that should not be covered to begin with because they trigger negative overall valuations; others may be introduced with a delay provided this produces sufficient cost savings, again to be passed on by premium reductions; and still others are valued highly enough to justify the increase in premiums caused by their extra cost.

Admittedly, these findings are based on experimental evidence which is subject to all sorts of bias. Experiments therefore need to be repeated to check for biases and to be validated by actual decisions. Moreover, there are additional contractual innovations that have not been examined in this paper. One such innovation is conditional 'carve-outs' in health insurance [21]. Illnesses that are known to shorten remaining life expectancy of elderly members are put into separate categories. They trigger a lump-sum payment covering the expected value of the associated healthcare expenditure. This illnessspecific indemnity insurance eliminates moral hazard because expenses in excess of the indemnity have to be paid by the insured. In the same vein, members who suffer from any illness causing a shortening of remaining life expectancy can be offered more generous coverage of the cost of long-term care [22] or increased annuities in pension insurance [23]. While these solutions provide welcome financial assistance to those affected, their indemnity characteristic again eliminates moral hazard.

In conclusion, the contractual innovations presented in this paper hold the promise that mitigating the 'cost explosion just before death' is not a hopeless endeavor. Since private health insurers are not bound to the solidarity principle calling for equal contributions regardless of true risk, they are better poised than social insurance schemes to launch these innovations of this. As for policymakers, the simple 
Citation: Zweifel P (2015) Aging of Society and New Medical Technology: The Challenge for Health Insurers to Meet the Expectations of Consumers and Governments. Aging Sci 3: 138. doi:10.4172/2329-8847.1000138

Page 8 of 8

suggestion that follows is 'laissez faire', i.e. to alleviate rather than further increase regulatory burdens that hamper product innovation.

\section{References}

Lichtenberg FR (2001) Are the benefits of newer drugs worth their cost? Evidence from the 1996 MEPS. Health Aff (Millwood) 20: 241-251.

Kotlikoff J and Raffelhüschen B (1999) Generational accounting around the globe. American Economic Review 89: 161-166.

Zweifel P, Felder S, Meier M (1999) Ageing of population and health care expenditure: a red herring? Health Econ 8: 485-496.

Rowe JW, Kahn RL (1997) Successful aging. Gerontologist 37: 433-440.

Phelan EA, Anderson LA, LaCroix AZ, Larson EB (2004) Older adults' views of "successful aging"-how do they compare with researchers' definitions? J Am Geriatr Soc 52: 211-216.

Newhouse JP (1992) Medical care costs: how much welfare loss? J Econ Perspect 6: 3-21.

Leukert-Becker K, Zweifel P (2014) Preferences for health insurance in Germany and the Netherlands - a tale of two countries. Health Econ Rev 4: 22.

Zweifel P, Telser H, Vaterlaus S (2006) Consumer resistance against regulation: the case of health care. Journal of Regulatory Economics 29: 319-332.

Telser H, Zweifel P (2000) Prävention von Schenkelhalsfrakturen durch Hüftprotektoren. Eine ökonomische Analyse. (Prevention of Fractures of the Femur Using Hip Protectors. An Economic Analysis), Bern: bfu Schweizerische Stelle für Unfallverhütung.

Sennhauser M, Zweifel P (2010) Willingness-to-pay for a new pharmaceutical: is it worth the money? Whose money? Forthcoming in: Jakovljevie, MB (ed.) Health Economics and Policy Challenges in Global Emerging Markets. NOVA Publishers, Hauppauge NY.

Schoder J, Zweifel P (2011) Flat-of-the-curve medicine: a new perspective on the production of health. Health Econ Rev 1: 2.

Cambois E, Robine JM (1996) An international comparison of trends in disability-free life expectancy. In: Eisen R, Sloan FA (eds.) Long-term Care: Economic Issues and Policy Solutions. Kluwer, Norwell MA, pp.11-23.

Zweifel P, Felder S, Meier M (1999) Ageing of population and health care expenditure: a red herring? Health Econ 8: 485-496.
Zweifel P, Becker-Leukert K (2007) Neue Versorgungsmodelle im Gesundheitswesen. Gestaltungsoptionen und Versichertenpräferenzen im internationalen Vergleich - Schlussbericht (New Modes of Providing Health Care, International Comparison of Design Options and Consumer Preferences - Final Report). Gütersloh (Germany): Bertelsmann Stiftung.

Eeckhoudt L, Schlesinger H (2006) Putting risk at its proper place. American Economic Review 96: 280-289.

Becker K, Zweifel P (2008) Age and choice in health insurance: evidence from a discrete choice experiment. Patient 1:27-40.

Okunade AA, Murthy VN (2002) Technology as a 'major driver' of health care costs: a cointegration analysis of the Newhouse conjecture. J Health Econ 21: $147-159$.

US Congressional Budget Office (2008) Technological Change and the Growth of Health Care Spending. Government Printing Office, Washington DC.

Weisbrod BA (1991) The health care quadrilemma: an essay on technological change, insurance, quality of care, and cost containment. Journal of Economic Literature 29: 523-552.

Gemmill, M, Serra-Sastre, V, and Costa-Font J (2009) Health insurance and the uptake of new drugs in the United States. In: CostaFont J, Courbage C, McGuire A (eds.), The Economics of New Health Technologies. Incentives, Organization, and Financing. Oxford University Press, Oxford. ch. 7.

Eppert T (2013) Critical illness for the elderly - risks and opportunities. Presentation at the 10th Geneva Association Health and Ageing Conference, "Insuring the health of an ageing population", Rüschlikon/Zurich (Switzerland).

de Montesquieu L (2013) Long-term care insurance products: standard and innovations. Presentation at the 10th Geneva Association Health and Ageing Conference, "Insuring the health of an ageing population", Rüschlikon/Zurich (Switzerland)

Banthrope P (2013) The development of impaired annuity markets in the UK and elsewhere. Presentation at the 10th Geneva Association Health and Ageing Conference, "Insuring the health of an ageing population", Rüschlikon/ Zurich (Switzerland). 